\title{
Variation of Non-Motor Neurological Symptoms of Parkinson's disease Patients
}

\author{
Afzal Momin'1, Md. Enayet Ul Islam², Farzana Sharmin³, Mohammad Enayet Hussain ${ }^{4}$, Md. Azharul Hoque \\ ${ }^{1}$ Associate Professor, Department of Clinical Neurology, National Institute of Neurosciences \& Hospital, Dhaka, Bangladesh; ${ }^{2}$ Assistant \\ Professor, Department of Neurology, National Institute of Neurosciences \& Hospital, Dhaka, Bangladesh; ${ }^{3}$ Assistant Professor, Department \\ of Gynaecology\& Obstetrics, Bangabandhu Sheikh Mujib Medical University, Dhaka, Bangladesh; ${ }^{4}$ Associate professor, Department of \\ Neurology, National Institute of Neurosciences \& Hospital, Dhaka, Bangladesh; ${ }^{5}$ Professor \& Head, Department of Neurology, National \\ Institute of Neurosciences \& Hospital, Dhaka, Bangladesh
}

[Received: 12 April 2019; Accepted: 20 May 2019; Published: 1 July 2019]

\begin{abstract}
Background: Different non-motor neurological complaints are reported among the Parkinson's disease patients. Objective: The purpose of the present study was to see the non-motor neurological complaints of Parkinson's disease patients. Methodology: This cross-sectional study was carried out in the in-patient and out-patient Department of Medicine and Neurology of Sir Salimullah Medical College and Mitford Hospital, Dhaka from July 2012 to December 2013 for a period of one and half year. All patients with Parkinson's disease who were admitted under department of Medicine and Neurology and also who visited out-patient department of Medicine and Neurology of Sir Salimullah Medical College and Mitford Hospital, Dhaka were included as study population. Patients who were diagnosed according to Brain Bank clinical criteria for diagnosis of Parkinson's disease were included in this study. The non-motor neurological complaints were recorded. Result: This study was conducted in Sir Salimullah Medical College and Mitford Hospital with a view to see the non-motor neurological complaints of Parkinson's disease. The mean age was found $69.15 \pm 10.08$ years. Most of the patients had a combination of non-motor symptoms and among them more than two third $(66.7 \%)$ of the patients had cognitive impairment; furthermore more than half $(53.8 \%)$ of the patients had sleep disturbance. One fourth $(25.0 \%)$ of patients had sensory, sleep and cognitive disorder; however, $9(22.5 \%)$ patients had sleep and cognitive disorder. Conclusion: In conclusion majority Parkinson's disease patients are suffering from cognitive impairment followed by sleep disturbances. [Journal of National Institute of Neurosciences Bangladesh, 2019;5(2):123-126]
\end{abstract}

Keywords: Non-Motor Complaints; Parkinson's disease; neurological problem

Correspondence: Dr. Afzal Momin, Associate Professor, Department of Clinical Neurology, National Institute of Neurosciences \& Hospital, Sher e Bangla Nagar, Agargaon, Dhaka 1207, Bangladesh; Email: afzal4474m@yahoo.co.in; Cell no.: +8801716802081

Conflict of interest: There is no conflict of interest relevant to this paper to disclose.

Funding agency: This research project was not funded by any group or any institution.

Contribution to authors: Momin A, Islam MEUcontributed from the protocol preparation, data collection up to report writing. Manuscript writing was performed by Sharmin F, Hussain ME; Momin A, Islam MEUhelped in statistical analysis. Hoque MAwas involved from the very beginning of this research work up to the revision of the manuscript as a supervisor.

How to cite this article: Momin A, Islam MEU, Sharmin F, Hussain ME, Hoque MA. Variation of Non-Motor Neurological Symptoms of Parkinson's disease Patients. J NatlInstNeurosci Bangladesh, 2019;5(2): 123-126

Copyright: (C2019. Momin et al. Published by Journal of National Institute of Neurosciences Bangladesh. This article is published under the Creative Commons CC BY-NC License (https://creativecommons.org/licenses/by-nc/4.0/). This license permits use, distribution and reproduction in any medium, provided the original work is properly cited, and is not used for commercial purposes.

\section{Introduction}

Regarding aetiology of Parkinson's disease, abnormal dopaminergic neurotransmission in the basal ganglia is observed which leads to a reduction in striatal dopamine content ${ }^{1}$. Dopamine deficiency causes resting tremor, bradykinesia, muscle rigidity, postural instability, forward-flexed posture, and freezing ${ }^{2}$. Additional symptoms occurring in this group of patients also include sensory symptoms, gastrointestinal disorders and dysphagia, depression, anxiety, and sleep disorders ${ }^{3}$.

There are several non-motor symptoms reported in Parkinson's disease patients ${ }^{4}$. Thus, non-motor symptoms are a common and underappreciated feature of Parkinson's disease. These include autonomic dysfunction, cognitive/neurobehavioral disorders, and sensory and sleep abnormalities ${ }^{5}$. Most Parkinson's disease occurs sporadically (85-90\%) and are of unknown cause. Twin studies suggest that environmental 
factors play more important role in patients older than 50 years, with genetic factors being more important in younger patients. Epidemiologic studies suggest increased risk with exposure to pesticides, rural living, and drinking well water and reduced risk with cigarette smoking and caffeine ${ }^{6}$.

Factors that have been implicated in the pathogenesis of cell death include oxidative stress, intracellular calcium accumulation with excitotoxicity, inflammation, mitochondrial dysfunction and proteolytic stress ${ }^{7}$. The purpose of the present study was to see the non-motor neurological complaints of Parkinson's disease patients.

\section{Methodology}

This cross-sectional study was carried out in the in-patient and out-patient Department of Medicine and Neurology of Sir Salimullah Medical College and Mitford Hospital, Dhaka from July 2012 to December 2013 for a period of one and half year.All patients with Parkinson's disease who were admitted under department of Medicine and Neurology and also who visited out-patient department of Medicine and Neurology of Sir Salimullah Medical College and Mitford Hospital, Dhaka were taken as study population. Patients who were diagnosed according to Brain Bank clinical criteria for diagnosis of Parkinson's disease were included in this study.The different non-motor neurological complaints were recorded in a semi-structured questionnaire. Respondents were selected by non-probability purposive sampling method on the basis of willingness of the patients, attendants and inclusion criteria were applied which has been mentioned earlier.Before data collection, informed written consent was taken from patient himself/herself or his/her attendant. A semi-structured questionnaire and checklist was prepared for each patient. The interview schedule was made in Bengali which included questions related to the objects of the study. Data was collected by researcher himself. All the data were checked and edited after collection. Then the data were entered into computer and statistical analysis of the result was obtained by using Windows based computer software devised with statistical packages for Social Sciences (SPSS-16). The statistical terms includes in this study are mean, standard deviation, percentage. After collection, all data were checked for inadequacy, irrelevancy and inconsistency. All irrelevant and inconsistent data were corrected or discarded methodically. Prior to the commencement of this study, the research protocol was approved by the thesis committee of Sir Salimullah Medical College and
Mitford Hospital, Dhaka.

\section{Results}

This study was conducted in Sir Salimullah Medical College and Mitford Hospital with a view to see the socio-demographic characteristics of Parkinson's disease. All socio-demographic characteristics were noted. It was observed that $15(37.5 \%)$ patients belonged to age 71 to 80 years and their mean age was found $69.15 \pm 10.08$ years (Table 1).

Table 1: Distribution of the study population by age $(\mathrm{n}=40)$

\begin{tabular}{lcc}
\hline Age Group & Frequency & Percent \\
\hline Less than 60 Years & 10 & 25.0 \\
61 to 70 Years & 13 & 32.5 \\
More than 71 Years & 17 & 42.5 \\
Total & $\mathbf{4 0}$ & $\mathbf{1 0 0 . 0}$ \\
Mean \pm SD (Range) & $69.15 \pm 10.08$ (48 to 100) \\
\hline
\end{tabular}

Table 2 shows multiple responds for non-motor symptoms of the patients. It was observed that most of the patients had a combination of non-motor symptoms among them more than two third $(66.7 \%)$ of the patients had cognitive impairment, more than half $(53.8 \%)$ of the patients had sleep disturbance, $11(28.2 \%)$ patients had sensory disturbance and only $1(2.6 \%)$ patient had anosmia.

Table 2: Distribution of the study patients by non-motor symptoms $(\mathrm{n}=40)$

\begin{tabular}{lcc}
\hline Non motor symptoms & Frequency & Percent \\
\hline Cognitive disturbance & 26 & 65.5 \\
Sleep disturbance & 21 & 53.5 \\
Sensory disturbance & 11 & 27.5 \\
Anosmia & 1 & 2.5 \\
None & 11 & 27.5 \\
\hline
\end{tabular}

Table 3 shows combinations of non-motor symptoms of the patients. It was observed that one fourth $(25.0 \%)$

Table 3: Distribution of the study patients by combinations of non-motor symptoms $(\mathrm{n}=40)$

\begin{tabular}{lcc}
\hline Non motor symptoms & Frequency & Percent \\
\hline Disorder in sensory + sleep +cognitive & 10 & 25.0 \\
Disorder in sleep+ cognitive & 9 & 22.5 \\
sleep disturbance & 3 & 7.5 \\
cognitive disturbance & 7 & 17.5 \\
None & 11 & 27.5 \\
\hline
\end{tabular}


of patients had sensory, sleep and cognitive disorder, $9(22.5 \%)$ patients had sleep and cognitive disorder, moreover $3(7.5 \%)$ patients had only sleep disturbance, $7(15.0 \%)$ had only cognitive disturbance but $12(30.0 \%)$ had no non-motor symptom.

\section{Discussion}

This present study has been conducted to see the non-motor neurological complaints of Parkinson's disease patients. During the study period a total of 40 patients diagnosed as Parkinson's disease by Neurologist and Medicine specialist by clinical criteria admitted under Department of Medicine and Neurology and also visited outpatient Department of Medicine and Neurology of Sir Salimullah Medical College and Mitford Hospital, Dhaka are recruited for this study. In this study it has been observed that $37.5 \%$ patients are in 8th decade and their mean age is $69.15 \pm 10.08$ years. The range is varied which is 48 to 100 years. In a study $^{8}$ it has been reported that the mean age of male patients is $64.7 \pm 6.4$ years and the mean age of the female patients is $63.2 \pm 5.6$ years. Findley (2007) has mentioned in his study that one in seven patients with PD is under the age of 50 years, and there is an increase in prevalence with increasing age. In this study only $5 \%$ of patients were 50 years or below which is much lower than that of previous study. Multiple responds for non-motor symptoms of the patients are recorded in this study. It has been observed that most of the patients have a combination of non-motor symptoms among them more than two third $(66.7 \%)$ of the patients have cognitive impairment; more than half $(53.8 \%)$ of the patients have sleep disturbance and 11(28.2\%) patients have sensory disturbance and only $1(2.6 \%)$ patient has anosmia.

The combinations of non-motor symptoms of the patients are also recorded. It has been observed that one fourth $(25.0 \%)$ of patients havesensory, sleep and cognitive disorder; $9(22.5 \%)$ patients havesleep and cognitive disorder; moreover $3(7.5 \%)$ patients have only sleep disturbance; $7(15.0 \%)$ patients have only cognitive disturbance; however, $12(30.0 \%)$ patients have no non-motor symptom. Neuropsychiatric disturbances can be as disabling as motor symptoms. In a of PD it has been found that $84 \%$ of patients evaluated are showed cognitive decline and that $48 \%$ met the diagnostic criteria for dementia after 15 years of follow-up'. Another community based prospective study found that patients with PD are at almost sixfold increased risk for dementia ${ }^{10}$. PD related dementia is also associated with a number of other neuropsychiatric comorbidities. Among 537 such patients, depression (58\%), apathy (54\%), anxiety (49\%) and hallucinations (44\%) were frequently reported ${ }^{11}$. In a study of 114 patients with PD, $27.6 \%$ screened positive for depression during the average 14.6 months of follow-up; $40 \%$ were neither treated with antidepressants nor referred for further psychiatric evaluation ${ }^{12}$. In addition to cognitive and affective disorders, many patients with PD exhibit features of obsessive-compulsive and impulsive behaviour, such as craving especially for sweets $^{13}$, binge eating, compulsive foraging, hypersexuality, pathological gambling, compulsive shopping and punding, characterised by intense fascination with repetitive handling, examining, sorting and arranging of objects ${ }^{14}$. These behavioural symptoms, sometimes referred to as hedonistic homeostatic dysregulation, have been attributed to dopamine dysregulation syndrome associated with the use of dopaminergic drugs, particularly dopamine agonists; however, the mechanism of these aberrant behaviours is not well understood ${ }^{15}$. Cognitive and behavioural dysfunction in PD is not well understood, and its discussion is beyond the scope of this article; the reader is referred to some recent reviews of this topic ${ }^{16}$.

Although sleep disturbances like excessive sleepiness, sleep attacksare once largely attributed to the pharmacological therapy for $\mathrm{PD}^{17}$, some clinicians now believe that these features are an integral part of the disease $^{18}$. This is supported by the observation that rapid eye movement sleep behaviour disorder, which occurs in approximately one-third of patients with PD, is a substantial risk factor for the development of $\mathrm{PD}^{18}$. Rapid eye movement sleep behaviour disorder, now considered a pre-parkinsonian state, is characterised by an increase in violent dream content accompanied by talking, yelling, swearing, grabbing, punching, kicking, jumping and other dramatic, violent and potentially injurious motor activity which may also involve the bed partner ${ }^{11}$. Insomnia, particularly sleep fragmentation, is also frequent (50\% prevalence), but the occurrence is highly variable among patients? ${ }^{7}$. The sleep abnormalities observed in patients with PD may possibly be related to a $50 \%$ loss of hypocretin (orexin) neurons ${ }^{19}$. Although excessive daytime sleepiness may contribute to fatigue, this common symptom is also seen independently of sleepiness ${ }^{20}$.

Sensory symptoms such as olfactory dysfunction, pain, paresthesia, akathisia, oral pain and genital pain are frequent but are often not recognised as parkinsonian symptoms ${ }^{21}$. One study found that olfactory 
dysfunction (hyposmia) may be an early marker of PD; it correlated with a $10 \%$ increased risk for the disease 2 years later compared with other asymptomatic relatives ${ }^{22}$. A study involving 62 pairs of twins discordant for PD found that smell identification was reduced in twins affected with PD than in those who were asymptomatic ${ }^{23}$. It has been also postulated that olfactory dysfunction is related to either neuronal loss in the corticomedial amygdala or to decreased dopaminergic neurons in the olfactory bulb ${ }^{23}$.

\section{Conclusion}

In conclusion majority Parkinson's disease patients are suffering from cognitive impairment followed by sleep disturbances.

\section{References}

1. Zesiewicz TA, Sullivan KL, Hauser RA. Nonmotor symptoms of Parkinson's disease. Exp Rev Neurother 2006;6:1811-22

2. Pursiainen V, Haapaniemi TH, Korpelainen JT, et al. Sweating in Parkinsonian patients with wearing-off. MovDisord 2007;22:828-32

3. Senard JM, Rai S, Lapeyre-Mestre M, et al. Prevalence of orthostatic hypotension in Parkinson's disease. J NeurolNeurosurg Psychiatry 1997;63:584-9

4. Swinn L, Schrag A, Viswanathan R, et al. Sweating dysfunction in Parkinson's disease. MovDisord 2003;18:1459-63

5. Allcock LM, Ullyart K, Kenny RA, et al. Frequency of orthostatic hypotension in a community based cohort of patients with Parkinson's disease. J NeurolNeurosurg Psychiatry 2004;75:1470-1

6. Hely MA, Morris JGL, Reid WGJ, et al. Sydney Multicenter Study of Parkinson's disease: non-L-dopa-responsive problems dominate at 15 years. MovDisord 2005;20:190-9

7. Aarsland D, Andersen K, Larsen JP, et al. Risk of dementia in Parkinson's disease: a community-based, prospective study. Neurology 2001;56:730-6

8. Aarsland D, Bronnick K, Ehrt U, et al. Neuropsychiatric symptoms in patients with Parkinson's disease and dementia: frequency, profile and associated care giver stress. J NeurolNeurosurg Psychiatry 2007;78:36-42

9. Ravina B, Camicioli R, Como PG, et al. The impact of depressive symptoms in early Parkinson disease. Neurology 2007;69:342-7

10. Palmiter RD. Is dopamine a physiologically relevant mediator of feeding behavior? Trends Neurosci 2007;30:375-81

11. Miyasaki JM, Al HK, Lang AE, et al. Punding prevalence in Parkinson's disease. MovDisord 2007;22:1179-81

12. Weintraub D, Siderowf AD, Potenza MN, et al. Association of dopamine agonist use with impulse control disorders in Parkinson disease. Arch Neurol 2006;63:969- 73

13. Sawamoto N, Honda M, Hanakawa T, et al. Cognitive slowing in Parkinson disease is accompanied by hypofunctioning of the striatum. Neurology 2007;68:1062-8

14. Ondo WG, DatVuong K, Khan H, et al. Daytime sleepiness and other sleep disorders in Parkinson's disease. Neurology 2001;57:1392-6

15. Gjerstad MD, Alves G, Wentzel-Larsen T, et al. Excessive daytime sleepiness in Parkinson disease: is it the drugs or the disease? Neurology 2006;67:853-8

16. Schenck CH, Bundlie SR, Mahowald MW. Delayed emergence of a parkinsonian disorder in $38 \%$ of 29 older men initially diagnosed with idiopathic rapid eye movement sleep behavior disorder. Neurology 1996;46:388-93

17. Plazzi G, Corsini R, Provini F, et al. REM sleep behavior disorders in multiple system atrophy. Neurology 1997;48:1094-7 18. Gagnon J-F, Postuma RB, Mazza S, et al. Rapid-eye-movement sleep behaviour disorder and neurodegenerative diseases. Lancet Neurol 2006;5:424-32

19. Borek LL, Kohn R, Friedman JH. Phenomenology of dreams in Parkinson's disease. MovDisord 2007;22:198-202

20. Gjerstad MD, Wentzel-Larsen T, Aarsland D, et al. Insomnia in Parkinson's disease: frequency and progression over time. J NeurolNeurosurg Psychiatry 2007;78:476-9

21. Boeve BF, Silber MH, Saper CB, et al. Pathophysiology of REM sleep behaviour disorder and relevance to neurodegenerative disease. Brain 2007;130(Pt 11):2770- 88

22. Fronczek R, Overeem S, Lee SY, et al. Hypocretin (orexin) loss in Parkinson's disease. Brain 2007;130:1577-85

23. Thannickal TC, Lai YY, Siegel JM. Hypocretin (orexin) cell loss in Parkinson's disease. Brain 2007;130:1586-95. 